\title{
Teachers' Demographic Profile on the Learners' Performance Using K-12 Earth and Space module
}

\author{
Vebhie Joy C. Salvan, LPT, MSciEd \\ Faculty, Department of Science, Mathematics, IT and Research \\ Integrated Developmental School \\ College of Education and Social Sciences \\ Mindanao State University at Naawan \\ Milagros M. Hambre, Ph.D. \\ Faculty, College of Education and Social Sciences \\ Mindanao State University at Naawan
}

\begin{abstract}
The purpose of this study is to determine the effect of the demographic profile ofK-12teachers who taught Earth and Space 9 subject to the academic performance of the learners using module. With the emergence of a new curriculum and a big change in the educational system, it is significant to determine the quality of teachers who have the great roles as the knowledge-imparters to the learners. This study also determines the learners' pre-test and post-test scores; the difference between learners' pre-test and post-test scores; the relationship between the learners' performance and the teachers' demographic profile. A total of 214 students and sixteen teachers from Naawan National High School (NaNHS) and Initao Comprehensive High School (INCHS) participated in the study. Based on the teachers' demographic profile results revealed that: there are more female than male teachers (67\% vs 33\%); $50 \%$ of them are within 27-32 years old and have been teaching for 22-26 years but most of them have only taught the subject Earth and Space for about 1-4 years(66.\%). Also, majority of the teachers are pursuing their Master's degree (66.7\%) and that $50 \%$ of them attended about 27-32 seminars and trainings up to the present. The performance in the pre-test of the learners from the two respondent schools is comparatively similar. However, the performance in the post-test of INCHS showed an increase in the number of learners who are at the Fairly Satisfactory level (54.6\%) and at the Satisfactory level (30.6\%) and has decreased in the number of learners (7.4\%) at Did not meet the Expectation level. On the other hand, NaNHS still has more learners that are at Did not meet the Expectation level (41.7\%) and only few learners are at Very Satisfactory level (36.1\%). Remarkably, none from the two schools reached the Outstanding level. Furthermore, a significant difference at $\alpha=0.05$ in the pre-test and post-test exists and there is no significant relationship between the performance of grade 9 learners and the teachers' demographic profile.
\end{abstract}

Keywords: Module, academic performance, demographic profile

\section{Introduction}

\subsection{Background and rationale}

One of the greatest reforms in the Philippine Educational System today is the implementation of the K to 12 program. The implementation of the K-12 curriculum in the Philippines started in 2012 beginning with grade 1 and grade 7 learners and the succeeding levels were introduced as these students got promoted to the next grade level in the ensuing school years. Priorto this, the Kindergarten Education Act was implemented in school year 2011-2012 by virtue of Republic Act 10157: the law institutionalized the inclusion of kindergarten education into the basic education system of the Philippines (PhilStar.com, 2012). Subsequently, Republic Act 10533 also known as the "Enhanced Basic Education Act of 2013" enabled the implementation of the K-12 in the country (The Official Gazette, 2013).

The enhanced K to 12 Basic Education Program seeks to provide for a quality 12 -year basic education program that each Filipino is entitled to. This is in cognizance with Article IV Section 2of the 1987Philippine Constitution which states that: "The state shall establish, maintain, and support a complete, adequate, and integrated system of education relevant to the needs of the people and society" (The Official Gazette, 2013).

With these scenarios, the DepEd lays high confidence on the K-12 Program in providing better quality of education that is based on spirally progressing curriculum starting with simple topics moving toward increasing complexity in order for the learners to gain mastery of concepts and skills. The use of spiral progression avoids disjunctions between stages 
of schooling and allows learners to learn topics and skills appropriate to their developmental and/or cognitive stages. The spiral progression is also believed to strengthen retention and mastery of topics and skills as they are revisited and consolidated with increasing depth and complexity of learning in the succeeding grade levels (Quijano and Technical Working Group on Curriculum, 2012).Also, the teaching approach used on this curriculum is more on hands-on, minds-on, and hearts on activities that are used to develop students' interest and let them become active learners instead of just relying solely on textbooks. In other words, the modular approach is widely applied to all subjects to meet the goal of K-12 curriculum which is to give every student an opportunity to receive quality education that is globally competitive. Modular teaching is one of the most widespread and recognized teaching learning technique in many countries including other Western countries and Asian region (Sejpal, 2013).

This emergence on basic education cycle caused the conduct of stakeholder consultations, policy discourses, and education summits to gather inputs and feedback on the educational reform, however, the $\mathrm{K}$ to 12 Program remains an issue of inquiries on its implementation and effectiveness. This lead the researcher to assess the module used in the instructions, the performance of the learners using the module and even the qualification and preparedness of the teachers who taught the subject matter. Specifically, the study would like to assess how teachers' demographic profile affect to the learner's performance in Earth and Space subject using K-12 module.

\subsection{Statement of the problem}

To attain the purpose of this study, the following research questions are addressed;

1. What is the demographic profile of the teacher in terms of:

a. Sex;

b. Age;

c.Educational attainment;

d. Length of service in teaching;

e. Number of years in teaching Earth and Space;

f. Number of seminars and trainings attended related to Science.

2. Wha tare the learners' pre-test and post-test scores in Earth and Space of Naawan National High School and Initao National Comprehensive High School;

3. What is the significant difference between the learners' pre-test and the post-test scores in Earth and Space;

4. What is the significant relationship between the learners' performance in Earth and Space and the teachers' demographic profile;

\subsection{Objectives}

\subsubsection{General objective}

This research focused on the effect of the implementation of the K-12 Module on Earth and Space to the performance of Grade 9 students

\subsubsection{Specific objectives}

Specifically, this study aims to:

1. Determine the demographic profile of the teacher in terms of:

a.Sex;

b.Age;

c.Educational attainment;

d.Length of service in teaching;

e.Number of years in teaching Earth and Space;

f.Number of seminars and trainings attended related to Science.

2. Determine the learners' pre-test and post-test scores in Earth and Space of Naawan National High School and Initao National Comprehensive High School;

3. Find out the significant difference between the learners' pre-test and the post-test scores in Earth and Space;

4. Find out the significant relationship between the learners' performance in Earth and Space and the teachers' demographic profile;

\subsection{Conceptual framework.}


Figure 1 shows the relationship of the teachers' demographic profile such as sex, age, educational attainment, length of service in teaching, numbers of years in teaching Earth and Space, and numbers seminars and trainings attended to the performance of the learners using the K-12 grade 9 Module in Earth and Space like teachers' guide for teachers and the learners' module for learners which contains of various learning activities.

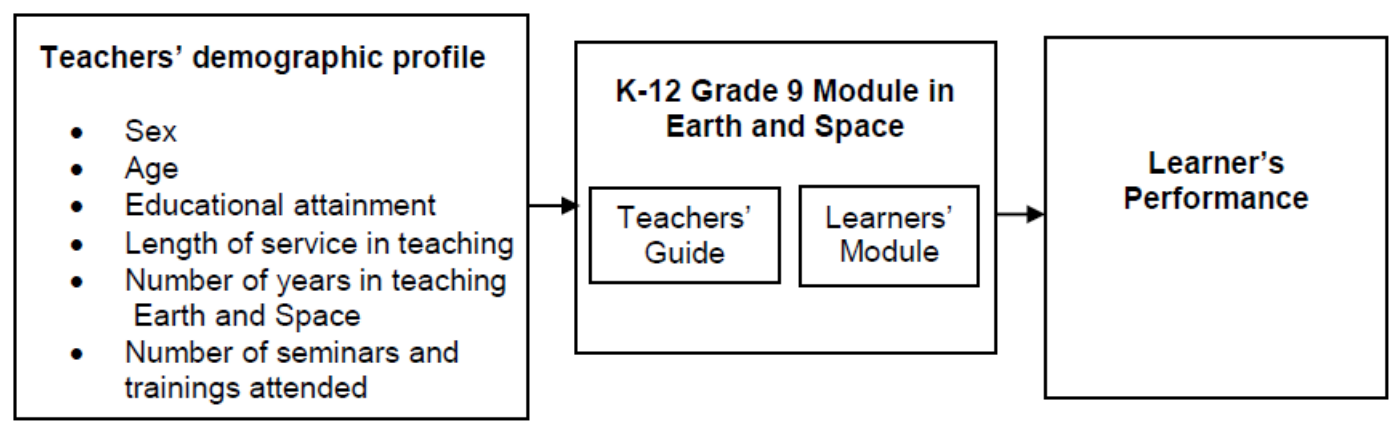

Figure 1. Conceptual framework of the study

\subsection{Significance of the study}

The findings of this study would be beneficial to teachers most especially to Learners, Science teachers, School administrators and Principals and Curriculum Developers.

Teachers will be more aware of the possible problems they are most likely to face when an adoption of a new curriculum takes place, thus, making them more prepared.

School administrators and .principals can gain insights as to what trainings and standard operating procedures should be given to teachers for the proper implementation of the new curriculum.

Curriculum developers could also gain appreciation of the curriculums strengths' and work on its weaknesses by making improvements.

\subsection{Scope and limitation of the study}

This study is limited on the effect of teachers' demographic profile to the learners' performance using Earth and Science Module.

\section{Learner's Performance}

Learners' Module

Teachers' Guide

\subsection{Definition of terms}

For better clarification and understanding of the terms related to this study, the following are defined operationally:

Academic performance refers to the result of the learner's pre-test and post-test in all activities given by the teacher and researcher

Demographic profile refers to teacher's age, gender, educational attainment, and length of service in teaching and seminars and training attended in teaching pedagogy and science.

Module refers to the learner's module developed and distributed by the DepEd for use in all public high schools. Specifically, it refers to the whole module of EarthScience (Unit III) for Grade 9

\section{Materials and method}

\subsection{Research design}

This study utilized a descriptive correlational research in the sense that it described the teachers' demographic profile, learners' performance and, correlational in the sense that it determined the relationship between the teachers' demographic profile and learners' performance.

\subsection{Subject of the study}

The subject of the study was the two hundred fourteen (214) grade 9 learners and sixteen (16) subject teachers in Earth and Space. 


\subsection{Data gathering procedure}

After the selection of the subject and the study area of the study, letter was sent to the Division Superintendent of the Department of Education in Region 10, asking permission to gather the necessary information concerning the teachers and their respective learners of the Initao National Comprehensive High School (INCHS) and Naawan National High School (NaNHS). With the approved letter of authorization, the corresponding Principals of the named public schools were informed about the conduct of the study. The subject teachers who participated in the study were identified and were also informed the same. With the permission of the schools' Principals, the questionnaires for pre-test were administered to the learners, the teachers' demographic profile were given to the teachers. At the end of the third grading, the questionnaires for post-test were also administered to the learners and the teachers answered the module evaluation questionnaire.

\subsection{Instrument used in the study}

The instruments used in the study were the learners' module, the Earth and Space unit test, and the teachers' demographic profile survey from

\subsubsection{The learners' module}

The learner's module is government-owned properties which were collaboratively developed and reviewed by the educators from public and private schools, colleges, and/or universities and distributed by the Department of Education to grade 9 of the K-12 Curriculum. Specifically, only Modules 1, 2 and 3 in Earth and Space for Grade 9 which were taken in the third quarter were used in the study.

\subsubsection{Earth and Space unit test}

For the pre-test, a 30-item unit test was given before the discussion on the unit of Earth and Space. Some items of the test were self-made following the K-12 assessment guidelines, the appropriate learning standard and the learning competencies of the Grade 9 adapted from the K-12 module.

2.4.3. Teachers' demographic profile survey form. The teachers' demographic profile were made with various array of items like teacher's age, sex, educational attainment, and length of service in teaching, number of years in teaching Earth and Science and numbers of seminars and training attended with respect to science and K-12 curriculum.

\subsection{Statistical design}

The following were the statistical tools used in interpreting the data.

\section{Percentage Mean}

It was used to determine the percentage distribution of the teachers' demographic profile. It was also employed for the presenting the reflections on each category in the student's journal checklist for each activity in the three modules. The pretest and posttest scores of the Grade 9 learners were also presented using tool.

\section{Mean}

It was used to describe the result of the qualitative rating of the module assessed by learners, teachers and the teacher experts.

\section{Paired Sample t-test}

This statistical tool was used to compare the pre-test and the post-test scores of the students in Earth and Space unit test.

\section{Spearman Correlation}

This statistical tool was used to determine the significant relationship between teacher's demographic profile and the performance of Grade 9 learners.

\section{Result and Discussion}

3.1. Teachers' demographic profile in terms of sex, age, educational attainment, length of service in teaching, number of years in teaching Earth and Space and seminars and trainings attended

\subsubsection{Teachers' demographic profile in terms of sex}


The study reported that sixty seven percent $(67 \%)$ of the teachers are females and thirty three percent $(33 \%)$ of the teachers are males. This indicates that in teaching profession, there are more female than male teachers. Sex plays a vital role in different job performance whether in offices, teaching, or in field works. Various researches provided results how males and females vary in terms of their performance. Women were found to score higher than men on the interpersonal dimension (Stone,et. al.,2009).This findings support this study that there are more female teachers than male teachers. Wylie (2000) also supports the contention that is commonly recognized worldwide as causing concern that teaching continues to be an increasingly feminized profession. Research undertaken from the Scottish Executive (2005) noted that the proportion of men in the active teaching workforce had declined from $30 \%$ in 1994 to one quarter in 2003. It was also confirmed that this trend is continuing, by 2007, 76\% of all registered teachers were women.

In addition, Feldman (2007) found that high school students rated female teachers are higher than male teachers. Thus, it is probable that gender is a factor in students' evaluations of teaching, but that the relationship is a complex one (Basow, 2000).

\subsubsection{Teachers' demographic profile in terms of age}

In this study, $50 \%$ of teachers who participated have ages between 27 and 32 years old. This means that if the starting age of a teacher to enter a teaching profession right after graduation is 21 years old, then these teachers were just developing their teaching profession. Wylie (2000) points out that there is a rapidly growing number of young teachers, as might be expected from the large numbers participating in the Teacher Induction Scheme in the recent years.

\subsubsection{Teachers' demographic profile in terms of educational attainment}

The result of this study reveals that $66.7 \%$ of the teachers are pursuing their Master's degree program. About seventeen percent $(17 \%)$ of them have either obtained their Master's degree or are pursuing doctorate programs. Teachers are required to participate in professional development sessions and take additional college courses to keep their certification current. Getting a master's degree at the beginning of a teaching career gives educators more flexibility when it comes to choosing these later courses. This also provides educators with an opportunity to take even higherlevel courses, work toward a doctorate in education and connect with other experts in the field.

\subsubsection{Teachers' demographic profile in terms of length of service in teaching}

With regards to teaching experience, about $50 \%$ of the teachers have been teaching for a period of 22-26 years as shown in Figure 6. About, 16.7\% of them have served for 8-12 years, 18-22 years, and 27-32 years, respectively.

In addition, Feldman (2007) found that high school students rated female teachers are higher than male teachers. Thus, it is probable that gender is a factor in students' evaluations of teaching, but that the relationship is a complex one (Basow, 2000).

\subsubsection{Teachers' demographic profile in terms of age}

In this study, 50\% of teachers who participated have ages between 27 and 32 years old. This means that if the starting age of a teacher to enter a teaching profession right after graduation is 21 years old, then these teachers were just developing their teaching profession. Wylie (2000) points out that there is a rapidly growing number of young teachers, as might be expected from the large numbers participating in the Teacher Induction Scheme in the recent years.

\subsubsection{Teachers' demographic profile in terms of educational attainment}

The result of this study reveals that $66.7 \%$ of the teachers are pursuing their Master's degree program. About seventeen percent $(17 \%)$ of them have either obtained their Master's degree or are pursuing doctorate programs. Teachers are required to participate in professional development sessions and take additional college courses to keep their certification current.

Getting a master's degree at the beginning of a teaching career gives educators more flexibility when it comes to choosing these later courses. This also provides educators with an opportunity to take even higher-level courses, work toward a doctorate in education and connect with other experts in the field.

\subsubsection{Teachers' demographic profile in terms of length of service in teaching}

With regards to teaching experience, about $50 \%$ of the teachers have been teaching for a period of 22-26 years as shown in Figure 6. About, 16.7\% of them have served for 8-12 years, 18-22 years, and 27-32 years, respectively. This study reported that most of the teachers $(50 \%)$ had rendered between 27-32 years in teaching. This means that they are more than two decades in the teaching services. Research shows that, on the average, teachers with more than 20 
years of experience are more effective than teachers with no experience, but are not much more effective than those with 5 years of experience (Ladd, 2008). Studies have also documented some evidence that effectiveness declines after some point, particularly among high school teachers. In fact, evidence suggests that the most experienced high school mathematics teachers greater than ( 25 years) may be less effective than their less experienced counterparts (Ladd, 2008) and even their inexperienced colleagues (Harris and Sass, 2007).

\subsubsection{Teachers' demographic profile in terms of number of years in teaching Earth and Space}

Figure 2presents that $67.7 \%$ of teachers have taught Earth and Space for 9-12 years and less than $20 \%$ of them have taught 5-8 years and 1-4 years, respectively.

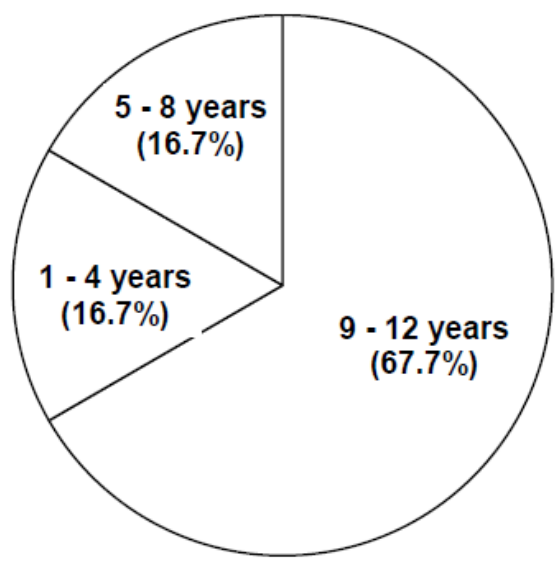

Figure 2. Percentage distribution of teachers' number of years in teaching Earth and Space

Teachers who participated in this study taught for a period of 9-12 years. This means that teachers have taught Earth and Science subject even before the implementation of the spiral progression of science K-12 curriculum. According to Darling-Hammond (2000) subject-matter knowledge has often been found to be an important factor in teachers' effectiveness. However, its relationship to teaching performance is curvilinear: it exerts a positive effect up to a threshold level and then tapers off in influence. Measures of pedagogical knowledge including knowledge of learning, teaching methods and curriculum have more often been found to influence teaching performance, and frequently these factors exert even stronger effects than subject matter knowledge.

\subsubsection{Teachers' demographic profile in terms of number of seminars and trainings attended}

Figure3presents that $50 \%$ of the teachers have attended between $27-32$ seminars and trainings, $33 \%$ of them have attended 15-30 seminars and trainings and only 17\% attended the least number, about 9-14 of seminars and trainings.

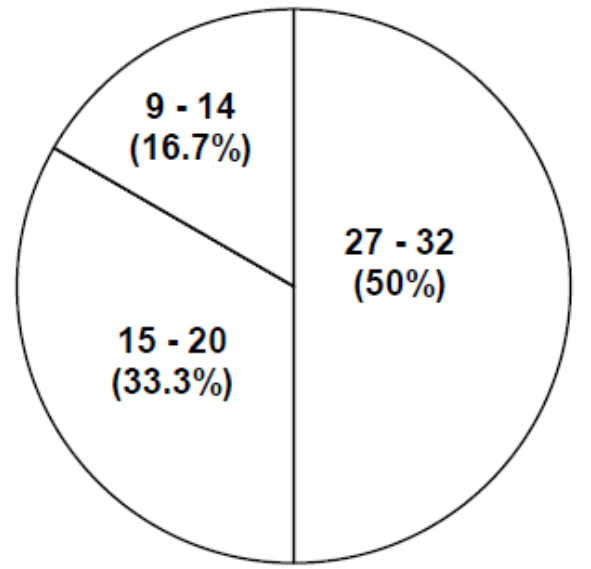

Figure 3. Percentage distribution of teachers' number of attended seminars and trainings related to science and K-12curriculum

The primary aim of teacher training is to develop educational skills. Result shows that $50 \%$ of the teachers attended between 27-32 seminars and trainings in their specialized subject and in teaching pedagogy. 
Teachers of K-12 attend seminars and trainings for several reasons like; to uplift their knowledge on K-12and to have knowledge on different strategies in teaching the lesson, as well as the new method of assessing pupils in such criteria: the (KPUP) Knowledge, Process, Understanding, Performance or Project(Enhanced Basic Education Act, 2013).

\subsection{Learners' pre-test scores in Earth and Space of Naawan National High School (NaHNS) and Initao National Comprehensive High School (INCHS)}

The results of the pre-test in Figure 4shows that both of the schools, the Naawan National High School (NaNHS) and the Initao National Comprehensive High School (INCHS) obtained comparatively similar results of $44.4 \%$ and 45.4 , respectively. Both schools did not meet the expectation; $45.4 \%$ and $43.5 \%$ in fairly satisfactory; $11.1 \%$ and $7.4 \%$ in satisfactory; and only NaNHS got very satisfactory level at $0.9 \%$. Both schools never reached the outstanding level in the pre-test.

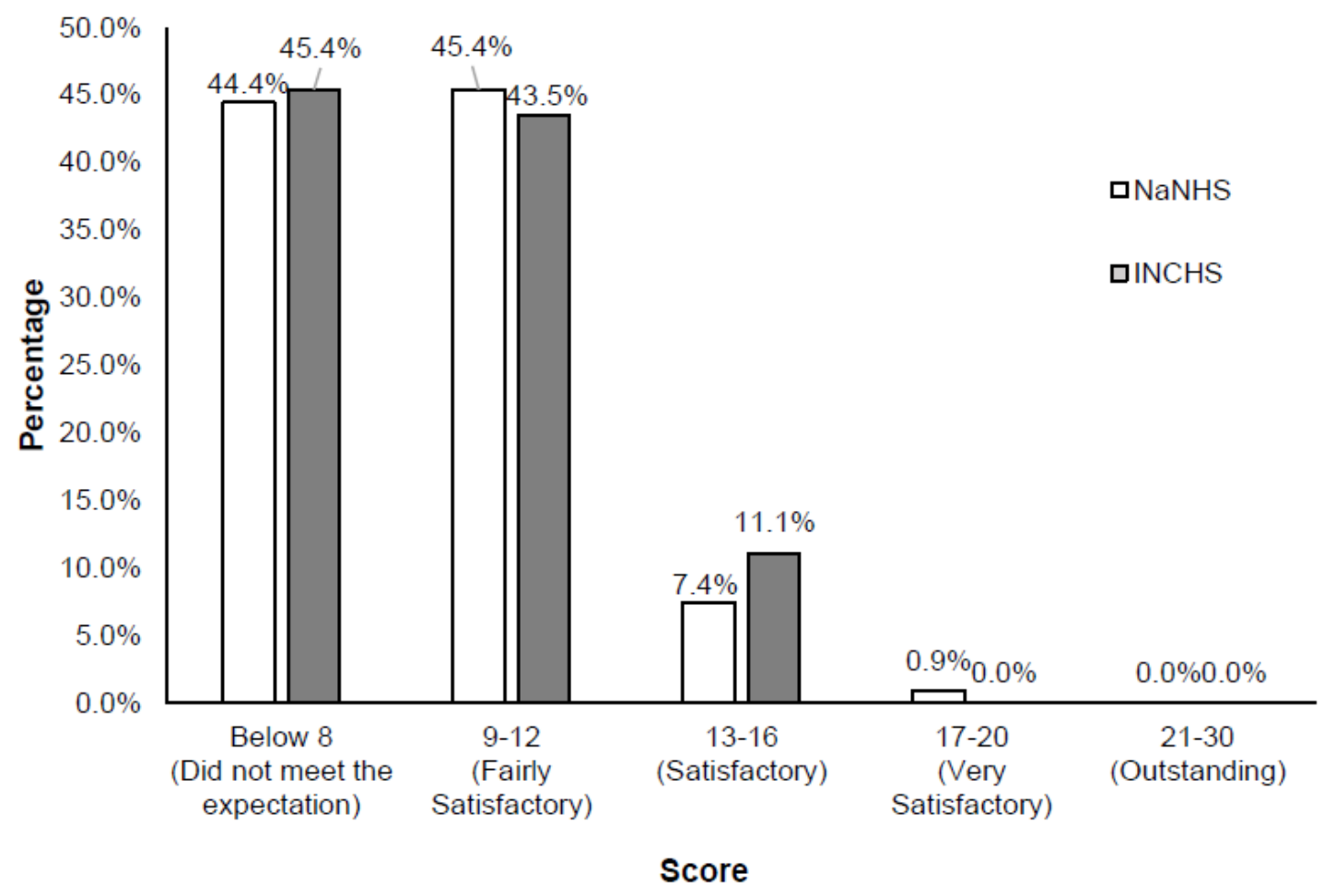

Figure 4. Percentage distribution of the learners' pre-test scores in Earth and Space of Naawan National High School (NaNHS) and Initao National Comprehensive High School (INCHS)

\subsection{Learners' post-test scores in Earth and Space of Naawan National High School (NaHNS) and Initao National Comprehensive High School (INCHS)}

Figure 5presents the post-test scores of the two public high schools. This results indicate that Naawan National High School (NaNHS) has the highest percentage $(41.7 \%)$ of the learners who did not meet the expectation level, $36.1 \%$ in fairly satisfactory, $16.7 \%$ in satisfactory and $3.7 \%$ in very satisfactory. The same figure presents the post-test result of Initao National Comprehensive High School (INCHS). This school has a tremendous decrease of learners (7.4\%) who did not meet the expectation level. However, there is an increase of the learners (54.6\%) in fairly satisfactory level. About $30.6 \%$ of learners are at the satisfactory and $7.4 \%$ in very satisfactory. None from the two schools reached the outstanding level in the post-test. 


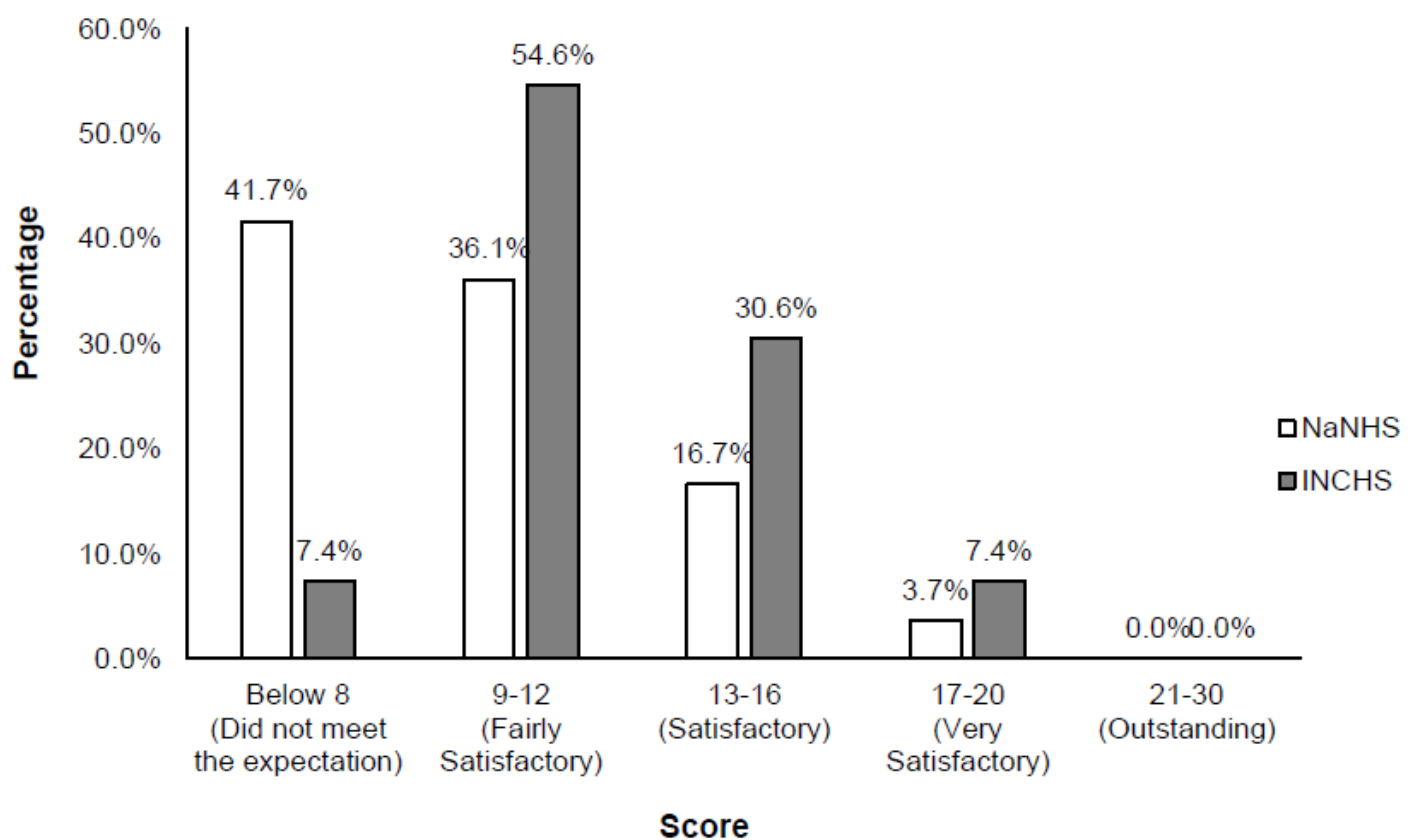

Figure 5. Percentage distribution of the learners' post-test scores in Earth and Space of Naawan National High School (NaNHS) and Initao National Comprehensive High School (INCHS)

\subsection{Difference in the learners' pre-test scores and post-test scores in Earth and Space}

The results in Table 1show that there is a significant difference between the pre-test and the post-test scores of Initao National Comprehensive High School (INCHS) as shown in the $t$-value of -10.66 and $p$-value of 1.65E-18 while there is no significant difference in pre-test and post-test of Naawan National High Schools (NaNHS) as shown in $t$-value of -1.72 and $p$-value of $8.89 \mathrm{E}-02$. However, the overall results of two public high schools have significant difference at 0.05 level of significance.

Table 1. Significant difference between pre-test and post-test scores in Earth and Space

\begin{tabular}{lllllll}
\hline School & $\mathbf{n}$ & $\begin{array}{l}\text { Mean } \\
\text { (Pretest- } \\
\text { Posttest) }\end{array}$ & $\begin{array}{l}\text { Mean } \\
\text { Difference }\end{array}$ & t-value & p-value & Remarks \\
\hline INCHS & 108 & $8.91-12.07$ & -3.157 & -10.66 & $1.65 \mathrm{E}-18$ & Significant \\
NaNHS & 106 & $9.07-9.61$ & -0.547 & -1.72 & $8.89 \mathrm{E}-02$ & Not Significant \\
Over-all & $\mathbf{2 1 4}$ & $\mathbf{8 . 9 7 - 1 0 . 8 5}$ & $\mathbf{- 1 . 8 6 4}$ & $\mathbf{- 7 . 9 5 0}$ & $\mathbf{1 . 1 0 E - 1 3}$ & Significant \\
\hline
\end{tabular}

Statistical analysis reveals that there is a significant difference between the pre-test and post-test scores of the students in this study. This means that after the series of discussions and activities given by the teachers, the performance of their students eventually increase.

\subsection{Relationship between the learners' performance in Earth and Space and the teachers' demographic profile}

As indicated in Table 6, there is no significant relationship between the learners' performance and in any variables in the teachers' demographic profile like the sex $(r=0.099, p>0.05)$, age $(r=0.1429, p>0.05)$; educational attainment $(\mathrm{r}=7.00, p>0.05)$; length of service in teaching $(r=-0.1449, p>0.05)$; number of years in teaching Earth and Space $(r=0.0911, p>0.05)$; and number of seminars and trainings attended related to Science and K-12 curriculum $(r=0.2319$, $p>0.05)$. 
Table 2. Spearman correlation results on the relationship between teachers' demographic profile and the learner's performance in Earth and Space

\begin{tabular}{lccl}
\hline Demographic Profile & r-value & p-value & Remarks \\
\hline Sex & 0.099 & 0.852 & Not Significant \\
Age & 0.1429 & 0.7872 & Not Significant \\
Educational attainment & 7.00 & 0.1359 & Not Significant \\
Length of service in teaching & -0.1449 & 0.7841 & Not Significant \\
No. of years in teaching Earth and Space & 0.0911 & 0.8638 & Not Significant \\
No. of seminars and trainings attended & 0.2319 & 0.6584 & Not Significant \\
\hline
\end{tabular}

The teachers' sex did not significantly affect academic achievement of the learners $(r=0.099, p>0.05)$. The finding concurs with Akiri (2008) that there was no significant relationship between teachers' sex and the academic achievement. Similar findings were obtained in an international study that was conducted by Burusic, et.al.,(2012) that the interaction effects of teachers' sex on school achievement are generally insignificant. However, the study conducted by Thomas (2006) confirms that a teachers' sex does have large effects on student test performance, teacher perceptions of students, and students' engagement with academic material. Additional findings in that study point out that girls have better educational outcomes when taught by women and boys are better off when taught by men. These findings persist, even after accounting a variety of other characteristics of students, teachers, and classrooms that may influence student learning.

Results show that the relationship value between age and performance is $r=0.1429, p>0.05$. This means that the findings of the study reveal that teachers' age is not a significant predictors on the learners' performance. This findings supported the study of E.E. Ebenuwa-Okoh (2010) reveal that gender, age and finance are not significant predictors of academic performance. There was no significant difference in academic performance based on age, gender and financial status. It was recommended that counselling centres should open to handle varying problems confronting student irrespective of age, financial status or gender.

This study also reveals that teachers' educational attainment $(r=7.00, p>0.05)$ has no influence on the performance in Earth and Space of Grade 9 learners. There are various studies that would support that teachers' educational level and their teaching experience were not statistically significant to students' academic achievement. It is therefore not surprising that Ravkin, etal., (2005) concluded that there was no evidence that a master's degree raises teacher effectiveness at secondary school level. Monk (1994) added that master's degree or any high degree attained had no influence on performance of the students. Teaching experience and highest degree earned alone is not possible to link the length and content of teacher education to students' achievement (Hanushek,et al., 1998).Contrary to the studies mentioned, Adeyemi(2010) points out that the professional qualification was a prime predictor of students' academic achievement. Conversely, Darling-Hammond (2000) emphasized that subject-matter knowledge has often been found to be an important factor in teacher effectiveness. However, its relationship to teaching performance is curvilinear: it exerts a positive effect up to a threshold level and then tapers off in influence. Measures of pedagogical knowledge including knowledge of learning, teaching methods and curriculum more often have been found to influence teaching performance, and frequently these factors exert even stronger effects than subject matter knowledge.

There are other characteristics of teachers that may also influence learners' performance. Teacher in-service training maybe positively related to student achievement. Conversely, this study reveals that teachers' length of service in teaching has no significant relationship to students' academic performance. Ravkin, et al., (2005) found that teachers' teaching experience and educational qualifications were not significantly related to students' achievement.

In sum, the results of this study do not provide strong evidence to indicate that the numbers of years of teaching in science strongly influences students' science achievement. Increased years of teaching experience in science might not lead to better student science achievement outcomes (Akiri, 2008). However, such findings could be useful from a policymaking perspective, as well as in considerations of teacher employment and training. For instance, increased years of teaching experience do not automatically translate into better qualified job candidates for teaching positions. Also, despite their individual amounts of experience, all teachers can develop effective teaching skills that can have benefits for their students in terms of learning outcomes.

\section{Summary and Conclusion}


1. The study was conducted in two identified public schools in Western Mindanao namely; Initao National Comprehensive High School and Naawan National High Schools using six high school teachers teaching Earth and Space in the School Year 2015-2016. The study sought to find out the following: (1) the demographic profile of teachers in terms of sex, age, educational attainment, length of service in teaching, number of years teaching Earth and Space subjects and the number of seminars and trainings attended; (2) the performance of the learners in the pretest and posttest; (3) the difference between pretest and post test scores; (4) the relationship between teachers' demographic profile and learners' performance and (5) the evaluation of the learners, the teachers and the experts on the grade 9 Earth and Space Module. Descriptive statistical tools like percentage, mean, paired t-test, and spearman correlation were used to gather the data.

2. The results of the study showed the following teachers' demographic profile. There are more female teachers $(67 \%)$ than male teachers (33\%);50\% of teachers have ages within the range of 27-32 years old; $50 \%$ of the teachers have served teaching for a period between 22-26 years; $67.7 \%$ of teachers rendered 1-4 years in teaching Earth and Space, $66.7 \%$ of the teachers are pursuing their Master's degree program; and lastly 50\% of teachers attended between 27-32 seminars and trainings from the time they have been in teaching.

3. The results in the learners' pre-test scores between the Naawan National High School (NaNHS) and the Initao National Comprehensive High School (INCHS) were comparatively similar. The pre-test scores of the former was $44.4 \%$ and the later was $45.4 \%$ and both where in the same level of did not meet the expectation with $45.4 \%$ and $43.5 \%$, respectively in the fairly satisfactory; $11.1 \%$ and $7.4 \%$, respectively, in satisfactory, and that only the NaNHS got very satisfactory level with $0.9 \%$. Both schools never reached the outstanding level in the pre-test.

4. After the third grading, the post-test was administered to determine if the learners have learned from the module. The results reveal that the Naawan National High School (NaNHS) has the highest percentage of the learners $(41.7 \%)$ who did not meet the expectation level, $36.1 \%$ in fairly satisfactory, $16.7 \%$ in satisfactory, and $3.7 \%$ in very satisfactorily. Initao National Comprehensive High School (INCHS) had a tremendous decrease of learners $7.4 \%$ in the posttest who did not meet the expectation level. Similarly, there was an increase of the learners (54.6\%) in the fairly satisfactory level. Also, $30.6 \%$ and $7.4 \%$ of the learners were at the satisfactory and very satisfactory, respectively. Remarkably, none from the two schools reached the outstanding level.

5. Findings showed that there was a significant difference in the pre-test and post-test tested at 0.05 level of significance.

6. This study found out that there was no significant relationship between the performance of grade 9 learners and the teachers' demographic profile like sex, age, educational attainment, length of service in teaching, number of years in teaching Earth and Space and number of seminars and trainings.

\section{Implications and Recommendation}

1. Science as one of the focus subject areas in the K-12 curriculum has been viewed as venue for honing students' talents obtained through various learning activities. The impact of the study may assist the need of the learners by providing them more venue of learning instructions to enhance their academic performance in science.

2. The K-12 Earth and Space module for grade 9 learners is effective instructional materials to use.

3. For future studies, it is recommended that the study may be conducted in the accredited private schools and public schools as the locale of the study to verify the evaluation of the learners on the content of the module.

4. The school and the parents should coordinate with each other to encourage the learners to improve academic performance through monitoring and follow-up of students' academic and co-curricular activities.

\section{Literature Cited}

Adeyemi, T. O. (2008). The Influence of Class-Size on the Quality of Output in Secondary Schools in Ekiti State, Nigeria. American-Eurasian Journal of Scientific Research 3(1): 7-14.

Akiri, A. A. \&Ugborugbo, N. M. (2008). An Examination of Genders Influence on Teachersproductivity in Secondary Schools. J. Soc. Sci, 17(3): 185-191.

Basow, S. A. (2000). Best and worst professors: Gender patterns in students' choices. Sex Roles:AJournal of Research, 34, 407-417.

Burusic, J., Babarovic, T., \&Seric,M. (2012). Differences in elementary school achievement between girls and boys: Does the teacher gender play a role? European Journal of Psychology of Education, 27(4), 523-538. 
Darling-Hammond, L. (2000). Teacher Quality and Student Achievement: A Review of State Policy Evidence. Stanford University. Retrieved on February7, 2010from http:// www.asu.edu/apaa.html

E.E. Ebenuwa-Okoh(2010)Influence of Age, Financial Status, and Gender on AcademicPerformance among Undergraduates, Journal of Psychology,1:2,99103,DOI:10.1080/09764224.2010.11885451

Feldman, K. A. (2007). Identifying exemplary teachers and teaching: Evidence from studentratings. In R. Perry \& J. Smart (Eds.), The scholarship of teaching and learning in highereducation: An evidence-based perspective (pp. 93-129). Dordrecht, TheNetherlands: Springer.

Hanushek, E. et. al. (1988). Teachers, schools, and academic achievement. [Online] Available: http://www.utdallas.edu/research/tsp/pulications.htm. (May 12, 2012).

Harris, Douglas N., and Tim R. Sass. 2007. "Teacher Training, Teacher Quality, and Student Achievement." CALDER Working Paper 3. Washington, DC: The Urban Institute.

Ladd, Helen F. 2008. "Value-Added Modeling of Teacher Credentials: Policy Implications." Paperpresented at the second annual CALDER research conference, "The Ins and Outs ofValue-Added Measures in Education: What Research Says," Washington, D.C.,

http://www. caldercenter.org/upload/Sunny_Ladd_presentation.pdf

Quijano, Yolanda S. \& technical Working Group on Curriculum ( 2012). Orientation for K to 12Division Coordinators. DepEd Complex. 25 June 2013.

Ravkin, S. G., et. al. (2005). Teachers, schools, and academic achievement.[Online] Available: http://www.utdallas.edu/research/tsp/pulications.htm. (May 12, 2012).

Republic Act 10533. Enhanced Basic Education Act of 2013.The Official Gazette. (Presidential Communications Development and Strategic Planning Office and PREGINET). Retrieved December 27, 2013 from http://www.gov.ph/

Scottish Executive. (2006), Scottish ExecutiveStatistical Publication, Education Series, Edn/G5/2007/2(27 March 2007), 24.

Sejpal, K. (2013). Modular method of teaching International Journal for Research in Education,2(2), 169171

Stone-Romero, E. F., Alvarez, K., \& Thompson, L. F. (2009). The construct validity of conceptualandoperational definitions of contextual performance and related constructs. HumanResource Management Review, 19, 104116

The K to 12 Basic Education Program. November 30, 2012by the Presidential Communication andStrategic Planning Office. Official Gazette. Official Journal of the Republic of the Philippines: http://www.gov.ph/k-12/

Thomas, D. S. (2006). The why chromosome: How a teacher's gender affects boys and girls. Stanford, CA: Education Next. Retrieved fromhttp://cepa.stanford.edu/sites/default/files/ednext20064_68.pdf 